\title{
LOS PROCESOS SECESIONISTAS Y EL DERECHO EUROPEO $^{1}$
}

\author{
JAVIER TAJADURA TEJADA \\ Catedrático (A) de Derecho Constitucional \\ Universidad del País Vasco
}

\section{SUMARIO}

I. El referéndum escocés y la apertura de la caja de Pandora. II. Significado y alcance del «derecho de secesión». III. La retirada de un Estado de la Unión Europea (secesión pactada). IV. La obligación de los Estados miembros de mantener su integridad territorial. V. Conclusiones: algunas propuestas para hacer frente al secesionismo.

\section{EL REFERÉNDUM ESCOCÉS Y LA APERTURA DE LA CAJA DE PANDORA}

Durante los días previos al referéndum sobre la independencia de Escocia del Reino Unido — celebrado el 18 de septiembre de 2014 - el mundo contuvo la respiración. Estaba en juego no sólo la integridad territorial de la segunda potencia militar de Occidente, sino la estabilidad económica y política de toda Europa. El contundente triunfo del no (11 puntos de diferencia) supuso un alivio considerable. Desde Washington hasta Bruselas, pasando por Berlín, el fracaso del independentismo fue recibido con júbilo en todas las cancillerías. Los mercados reaccionaron también positivamente. Los efectos de la victoria de los partidarios de la conservación del Reino Unido se propagaron por toda Europa conjurando - a corto plazo y en un futuro inmediato- los riesgos de desestabilización general del continente europeo provocados por el irresponsable comportamiento del Primer Ministro británico. Sin embargo, la celebración del referéndum de auto-

1 Este trabajo se enmarca en el Proyecto de Investigación «Historia conceptual, constitucionalismo y modernidad en España, en Europa y en el Mundo Iberoamericano. Una aproximación pluridisciplinar» (HAR2013-42779-P) financiado por el Ministerio de Economía y Competitividad. 
determinación se convirtió en un precedente digno de ser emulado por movimientos y fuerzas políticas nacionalistas de España, Italia, Bélgica, etc. La mera posibilidad de que el Reino Unido hubiera quedado fragmentado es un riesgo que ningún político sensato hubiera debido correr. Cameron no fue pragmático, fue arrogante. Si dos años antes hubiera planteado a los escoceses las propuestas de mayor autonomía que ofreció en las vísperas del referéndum, este podría y debía haberse evitado.

En el referéndum se impuso la sensatez. A pesar del contundente rechazo que suscitaban las políticas del gobierno conservador británico entre la población de Escocia (sólo 1 de los 60 diputados elegidos en los distritos electorales de Escocia pertenecía al Partido Conservador), la gran mayoría de los escoceses fue consciente de lo que realmente estaba en juego. Y lo que se votaba no era la aceptación o el rechazo de unas políticas concretas, sino el mantenimiento o la destrucción de una comunidad política que durante más de tres siglos había garantizado la convivencia en paz y en libertad.

El referéndum escocés supuso, en todo caso, la apertura de la caja de Pandora de la secesión. Apertura que llevó a la agenda política la posibilidad de fragmentar Estados con base en planteamientos —ideológicos y políticos- similares a los que hace exactamente cien años condujeron al suicidio de Europa.

Como es sabido, los efectos políticos disgregadores de «la ideología de la nación» se vieron reforzados por el Presidente Wilson, con la introducción en 1919 del principio de autodeterminación de las nacionalidades en virtud del cual las «naciones culturales» debían convertirse en Estados independientes². Ese principio sirvió para destruir comunidades políticas potencialmente inclusivas como el Imperio Austro-húngaro, para erigir fronteras, crear conflictos y sumir a Europa, veinte años después, en una nueva orgía de sangre. Sobre los escombros de una Europa destruida, y con el deseo de evitar una nueva guerra, dirigentes políticos dotados de una gran altura de miras y con sentido de la responsabilidad histórica sentaron las bases del proceso de integración europea. Proceso que se configura como el principal baluarte político, jurídico y moral contra los peligros del nacionalismo (estatal, o infraestatal).

Por todo ello, resulta un tanto incomprensible que la Unión Europea no haya reaccionado con mayor firmeza y contundencia ante unos actos (el referéndum de Escocia, el del Véneto o el catalán) que, desde una perspectiva política y axiológica, suponen un ataque a su línea de flotación, a su razón de ser, y a sus valores fundacionales; y desde una perspectiva jurídica, una violación manifiesta de los artículos 3 y 4 del Tratado de la Unión Europea (entre otros). El objeto de este artículo es poner de manifiesto la incompatibilidad existente entre cualquier pro-

2 Blas Guerrero, A. DE: «A vueltas con el principio de las nacionalidades y el derecho de autodeterminación» en Revista Internacional de Filosofía Política, n. ${ }^{\circ}$ 3, 1994. 
ceso secesionista en el interior de un Estado miembro con el Derecho europeo ${ }^{3}$, así como formular algunas propuestas tendentes a evitar que el referéndum escocés se configure como un precedente desestabilizador del proyecto de integración.

Con todo, el tema debe ser abordado en un marco más amplio, el referido a la problemática de la secesión no ya en el seno de un Estado Constitucional sino en el de la propia Unión Europea configurada como una Comunidad de Derecho en clave constitucional y federal. Ambas perspectivas se complementan.

En las elecciones legislativas del 7 de mayo de 2015, el Primer Ministro David Cameron obtuvo una mayoría absoluta amplia. En el discurso de la Reina pronunciado el 27 de mayo, incluyó dentro de su programa legislativo, la celebración de un referéndum sobre la permanencia del Reino Unido en la Unión Europea. El partido laborista — claramente partidario de la permanencia y que se había opuesto al referéndum en la campaña electoral — ha apoyado también el proyecto de ley ${ }^{4}$. La pregunta es la siguiente: «¿Debería el Reino Unido permanecer como miembro de la Unión Europea?» ${ }^{5}$. El referéndum debe celebrarse antes de 2017.

Este último órdago lanzado por David Cameron ha colocado de nuevo a la Unión Europea en una encrucijada decisiva. Es evidente que la Unión no puede aceptar lo que, a todas luces, se plantea como un evidente chantaje, pero no es ese el tema que aquí interesa. Lo que nos importa subrayar es que la eventual retirada británica de la Unión (secesión del Reino Unido respecto a la Unión Europea) reforzaría las posiciones independentistas escocesas. La secesión de Escocia del Reino Unido supondría, en ese caso, la única forma de poder ingresar como nuevo Estado en una Unión Europea de la que el Estado matriz se ha retirado ${ }^{6}$.

La posible retirada del Reino Unido de la Unión Europea y la eventual ruptura de Escocia con el Reino Unido se presentan, por tanto, como procesos políticamente interrelacionados. Procesos que, desde una perspectiva estrictamente jurídica nos obligan a examinar el significado y alcance de la secesión en el Dere-

3 Su incompatibilidad con el Derecho Constitucional interno es evidente salvo que se sostenga que los Estados no son per se indestructibles e indivisibles.

$4 \mathrm{El}$ proyecto de ley por el que se autoriza al Gobierno a celebrar un referéndum sobre la permanencia del Reino Unido en la UE antes del final de 2017 fue aprobado por la Cámara de los Comunes el 9 de junio de 2015 .

5 El Gobierno británico aceptó la versión recomendada por la Comisión Electoral del Reino Unido, frente a la propuesta del gobernante Partido Conservador, que prefería preguntar: «¿Piensa usted que el Reino Unido debería ser miembro de la Unión Europea?».

6 Todos los analistas han subrayado la relación entre ambos procesos. Así, el antiguo director de Le Monde, J. M. Colombani ha escrito: «La cuestión central para el primer ministro es la subsistencia o no de la unidad del reino. Los escoceses han rechazado la independencia en un referéndum, pero acto seguido han seguido votando mayoritariamente por los independentistas. Y tampoco hará falta espolear mucho a los galeses para que sigan el mismo camino. Si los electores británicos votaran por la salida de la Unión Europea, a los escoceses - que tienen reputación de ser más europeístas que los galeses_ sólo les quedaría pedir la adhesión. Por tanto, permanecer en Europa es para Londres la mejor garantía para preservar la unidad del reino de Gran Bretaña». Colombani, J. M.: «La unidad del reino» en EL PAIS, 10 de junio de 2015, p. 12. 
cho Internacional general, en el Derecho Constitucional y en el Derecho comunitario europeo.

\section{SIGNIFICADO Y ALCANCE DEL «DERECHO DE SECESIÓN»}

\section{La secesión en el Derecho Internacional}

La secesión, como ha advertido De Miguel, es un fenómeno histórico: «desde que prácticamente, en los albores de la modernidad, se fueron configurando y construyendo los Estados, han existido movimientos políticos enfocados a conseguir la separación de la organización política de la que forman parte» ${ }^{7}$. El concepto de secesión abarca, por tanto, procesos muy variados, que van desde las primeras segregaciones sufridas por los imperios coloniales británico y español durante los siglos XVIII y XIX hasta la dramática destrucción de Yugoeslavia en la última década de la pasada centuria.

Tras la trágica experiencia de las guerras mundiales, los Estados y diversas organizaciones internacionales - Naciones Unidas, Consejo de Europa, Organización para la Seguridad y la Cooperación en Europa, y la propia Unión Europea- se han enfrentado al problema de la secesión y lo han delimitado jurídicamente.

La secesión como derecho de una colectividad a independizarse de la comunidad política más amplia a la que pertenecen se identifica con el «derecho de autodeterminación de los pueblos». Este derecho está reconocido por la Resolución 1514 de la Asamblea General de la ONU de 1960 pero su aplicación se limita a los territorios sometidos a dominación colonial ${ }^{8}$.

7 De Miguel, J.: «La cuestión de la secesión en la Unión Europea: una visión constitucional» en Revista de Estudios Políticos, n. ${ }^{\circ}$ 165, 2014, p. 215.

8 «1. La sujeción de pueblos a una subyugación, dominación y explotación extranjeras constituye una denegación de los derechos humanos fundamentales, es contraria a la Carta de las Naciones Unidas y compromete la causa de la paz y de la cooperación mundiales. 2. Todos los pueblos tienen el derecho de libre determinación; en virtud de este derecho, determinan libremente su condición política y persiguen libremente su desarrollo económico, social y cultural. 3. La falta de preparación en el orden político, económico, social o educativo no deberá servir nunca de pretexto para retrasar la independencia. 4. A fin de que los pueblos dependientes puedan ejercer pacífica y libremente su derecho a la independencia completa, deberá cesar toda acción armada o toda medida represiva de cualquier índole dirigida contra ellos, y deberá respetarse la integridad de su territorio nacional. 5. En los territorios en fideicomiso y no autónomos y en todos los demás territorios que no han logrado aún su independencia deberán tomarse inmediatamente medidas para traspasar todos los poderes a los pueblos de esos territorios, sin condiciones ni reservas, en conformidad con su voluntad y sus deseos libremente expresados, y sin distinción de raza, credo, ni color, para permitirles gozar de una libertad y una independencia absolutas. 6. Todo intento encaminado a quebrantar total o parcialmente la unidad nacional y la integridad territorial de un país es incompatible con los propósitos y principios de la Carta de las Naciones Unidas. 7. Todos los Estados deberán observar fiel y estrictamente las disposiciones de la Carta de las Naciones Unidas, de la Declaración Universal de Derechos Humanos y de la presente Declaración sobre la base de la igualdad, de la no intervención en los asuntos internos de los demás Estados y del respeto de los derechos soberanos de todos los pueblos y de su integridad territorial». 
Diez años después, la Resolución 2625 de 1970 amplió su alcance a ámbitos distintos del colonial, pero lo supeditó al respeto al principio de integridad territorial y restringió su aplicación a aquellas situaciones en que una parte de la población sufre discriminación. El derecho se proclama en estos términos: «En virtud del principio de la igualdad de derechos y de la libre determinación de los pueblos, consagrado en la Carta, todos los pueblos tienen el derecho de determinar libremente, sin injerencia externa, su condición política y de proseguir su desarrollo económico, social y cultural, y todo Estado tiene el deber de respetar este derecho de conformidad con las disposiciones de la Carta». El respeto a la integridad territorial de los Estados se presenta como su contrapunto: «Ninguna de las disposiciones de los párrafos precedentes se entenderá en el sentido de que autoriza o fomenta cualquier acción encaminada a quebrantar o menospreciar, total o parcialmente, la integridad territorial de Estados soberanos e independientes que se conduzcan de conformidad con el principio de la igualdad de derechos y de la libre determinación de los pueblos antes descritos y estén, por tanto dotados de un gobierno que represente a la totalidad del pueblo perteneciente al territorio, sin distinción por motivo de raza, credo o color».

Esto quiere decir que, desde la óptica del Derecho Internacional, la existencia de un gobierno representativo «de la totalidad del pueblo perteneciente al territorio», priva de fundamento jurídico a cualquier pretensión secesionista, y consagra el derecho a la integridad territorial del Estado en cuestión.

El principio del respeto a la integridad territorial de los Estados se configura así como el elemento central del orden jurídico internacional. Como contrapartida, las organizaciones mencionadas han ido elaborando un amplio y notable acervo jurídico orientado a garantizar que las minorías nacionales tuvieran un status adecuado dentro de los ordenamientos constitucionales internos. La autonomía (regional o federal) constitucionalmente garantizada es el expediente empleado por los distintos Estados para proteger de forma efectiva a las minorías nacionales allí donde existan.

En este contexto, en la Europa de hoy, la única justificación que podría alegar una minoría nacional o cualquier otra colectividad, para reclamar la titularidad, y en su caso, ejercer el derecho de autodeterminación para separarse de un Estado y constituir otro independiente, sería que se tratase de un grupo de ciudadanos a los que se hubiese privado de sus derechos de representación y estuvieran, por tanto, sometidos a un régimen de opresión?.

Las meras demandas de reconocimiento político o simbólico, las reclamaciones fiscales o de determinado trato económico, no justifican en ningún caso la secesión. Es preciso que las minorías de que se trate sufran una situación de clara discriminación ${ }^{10}$.

9 Buchanan, A.: «Self - Determination and the Right to Secede», Journal of International Affairs, Vol. 45, n. ${ }^{\circ}$ 2, 1992, p. 349.

10 Buchanan, A.: Justice, Legitimacy, and Self-Determination: Moral Foun- dations for International Law, Oxford University Press, Oxford, 2004; Koskenniemi, M.: «National Self - Determination Today: 
En el ámbito de la Unión Europea, analizando la situación de los 28 Estados miembros de la Unión, únicamente en Letonia y Estonia en relación con la minoría rusa cabe apreciar esa situación ${ }^{11}$. Al margen de esas dos lamentables situaciones no existe en ningún Estado miembro población discriminada alguna.

En la medida en que para entrar en la UE es preciso que el Estado que se integre asuma en su ordenamiento y garantice efectivamente, los valores consagrados en el artículo 2 TUE (democracia, Estado de Derecho, respeto a los derechos fundamentales, incluidos los derechos de las personas pertenecientes a minorías) en ningún Estado miembro de la misma deberían concurrir nunca los supuestos que el Derecho Internacional exige para poder ejercer el derecho de autodeterminación y llevar a cabo una secesión.

Si en la práctica se plantearan estas situaciones — lo que a la vista del régimen jurídico aplicable a la minoría rusa en Letonia y Estonia no es una mera hipótesis- habría que acudir a lo dispuesto en el artículo 7 TUE. Este precepto prevé mecanismos de ejecución federal en forma de sanciones para quienes no garanticen y respeten los valores consagrados en el artículo 2 .

De todo lo anterior podemos concluir que el Derecho Internacional General no sólo no proporciona cobertura jurídica alguna a la secesión de una parte de un Estado miembro de la Unión, sino que, por el contrario, consagra el derecho a la integridad territorial de los Estados miembros.

\section{La secesión en el Derecho Constitucional}

Si del Derecho Internacional descendemos al ámbito del Derecho Constitucional interno, la cuestión es si cabe todavía más clara. Secesión y Constitución son términos incompatibles. La secesión constitucional es un «oxímoron jurídico» ${ }^{12}$. Ningún Estado y ninguna Constitución pueden prever mecanismos que faciliten su propia destrucción. La inclusión del derecho de autodeterminación en una Constitución colocaría a esta en una posición de norma transitoria, cuya vigencia plena (sobre la totalidad del territorio y la población del Estado) quedaría condicionada a que los titulares del derecho de autodeterminación no lo ejerciesen. Esa configuración como norma provisional o transitoria es incompatible con la posición de supremacía que jurídicamente caracteriza a toda Constitución normativa.

Problems of Legal Theory and Practice», International and Comparative Law Quarterly, Vol. 43, n.o 2, 1994; Weller, M. y Metzger, B. (eds.): Settling Self - Determination Disputes. Complex Power - Sharing in Theory and practice, Martinus Nijhoff Publishers, The Netherlands, 2008.

11 Debido a esta situación, Letonia y Estonia no deberían haber ingresado en la UE ni en el Consejo de Europa. Benedikter, T. (ed.): Europe's Ethnic Mosaic: A Short Guide of Minority Rights in Europe, EURAC, Bolzano, 2008, pp. 66 y ss.

12 De Miguel, J.: «El derecho a decidir y sus aporías democráticas» en Cuadernos de Alzate, n. ${ }^{\circ} 46-$ 47, 2013, pp. 161-174. 
Por otro lado, esa misma provisionalidad predicable del Estado es incompatible con su esencia. Ningún Estado se concibe como una comunidad política provisional. Antes bien, todo Estado, incluido el Federal, nace con vocación de perpetuidad. Por decirlo con las palabras utilizadas por el Tribunal Supremo para definir la naturaleza y caracteres de los EEUU: la Federación es «una Unión indestructible de Estados indestructibles» ${ }^{13}$.

Para quienes lo anterior no resulte evidente, basta recordar que de los 195 Estados en que está dividido el mundo, sólo dos —-Etiopía ${ }^{14}$ y San Cristóbal-Nevis (dos islas antillanas que comparten Estado ${ }^{15}$ ) — recogen en sus Textos Constitucionales cláusulas de secesión.

Todo lo anterior nos permite concluir que no existe la «secesión constitucional». Al margen de los dos supuestos citados — verdaderas excepciones que cumplen la función de confirmar la regla contraria_ la secesión es — por su propia naturaleza- un acto inconstitucional. Un acto cuya consecuencia es siempre la ruptura del Estado y la destrucción de la Constitución. Lo primero es difícilmente discutible. La secesión va a dar lugar a dos o más Estados donde antes sólo había uno. Respecto a lo segundo — que toda secesión supone la destrucción de la Constitución del Estado matriz - reina una cierta confusión. Detengámonos en esta cuestión.

Aunque toda secesión es inconstitucional, en la teoría y en la práctica es posible distinguir entre secesiones «unilaterales» y secesiones «pactadas o consensuadas» ${ }^{16}$. La distinción es útil para enfrentarnos a su estudio tanto en relación con procesos secesionistas dentro de un Estado, como en relación a la propia UE.

Un supuesto de secesión pactada es el procedimiento previsto por el Dictamen del Tribunal Supremo de Canadá en relación con Quebec. En su célebre decisión de 20 de agosto de $1998^{17}$, el Alto Tribunal canadiense, tras afirmar que el

13 Sentencia del Tribunal Supremo de los EE. UU, Texas vs White (1869). ReEd Amar, A.: «Of Soveregnity and Federalism» en The Yale Law Journal, Vol. 96, n. ${ }^{\circ}$ 7, 1987, pp. 1425 y ss. De Miguel, J.: «Secesión y Constitución en los Estados Unidos» en Cuadernos Manuel Gimenez Abad, n. ${ }^{\circ}$ 8, 2014, pp. 20 y ss.

14 El apartado 3 del artículo 47 de la constitución vigente en Etiopía —en vigor desde agosto de 1995 — regula así el derecho de secesión: «The right of any Nation, Nationality or People to form its own state is exercisable under the following procedures: a) When the demand for statehood has been approved by a two-thirds majority of the members of the Council of the Nation, Nationality or People concerned, and the demand is presented in writing to the State Council; b) When the Council that received the demand has organized a referendum within one year to be held in the Nation, Nationality or People that made the demand; c) When the demand for statehood is supported by a majority vote in the referendum; d) When the State Council will have transferred its powers to the Nation, Nationality or People that made the demand; and e) When the new State created by the referendum without any need for application, directly becomes a member of the Federal Democratic Republic of Ethiopia.»

15 La constitución de 1983 de San Cristóbal y Nevis concede a la isla de Nevis el derecho a separarse de la de San Cristóbal y elaborar una constitución propia si la decisión obtiene una mayoría en el Parlamento de la isla de dos tercios y es ratificada también por dos tercios de la población de la isla mediante referéndum.

16 De Miguel, J.: La cuestión de la secesión..., ob. cit., p. 228.

17 Chacón, C., y Ruiz Robledo, A.: «Comentario del Dictamen del Tribunal Supremo canadiense de 20 de agosto de 1998 sobre la secesión de Quebec» en Teoría y Realidad Constitucional, n. ${ }^{\circ}$ 3, 1999. 
derecho de autodeterminación o secesión no existe como tal en el ordenamiento jurídico interno, construye un método por el que a través del diálogo y la negociación, y mediante mayorías cualificadas sobre preguntas claras, podría lograrse la secesión. Se trata de una vía alternativa a la secesión unilateral, es decir, a la alcanzada mediante una Declaración unilateral de independencia. El caso escocés se configura también como otro supuesto de secesión pactada. El Parlamento británico convocó una consulta sobre la independencia, y se comprometió a negociar y pactar la ruptura, si en aquella hubiera triunfado la opción secesionista ${ }^{18}$.

Frente a los casos mencionados (Quebec y Escocia) en los que la eventual secesión será el resultado de un proceso político de dialogo entre el Estado y la entidad separatista, tenemos los supuestos de secesión «unilateral». El paradigma es Kosovo y cuenta con un marco normativo internacional propio: el Dictamen de la Corte Internacional de Justicia de 22 de julio de 2010. En esta controvertida resolución ${ }^{19}$ la Corte declaró que es posible que un acto como la Declaración unilateral de independencia, no infrinja el derecho internacional, sin que ello constituya tampoco el ejercicio de un derecho que este le pudiera conferir previamente. Ahora bien, de lo que no cabe ninguna duda es de que toda secesión unilateral supone una violación de la Constitución del Estado matriz.

Las dudas surgen, únicamente, en relación con las eventuales secesiones «consensuadas» o «pactadas». Para algunos autores, si la secesión se lleva a cabo conforme a Derecho, esta no sería «inconstitucional». En esos casos no cabría hablar de destrucción de la Constitución del Estado matriz. Ahora bien, si se acepta que la secesión no provoca la destrucción de la Constitución habría que admitir, al menos, que toda secesión implica una reforma de aquella ${ }^{20}$. Y ello porque sería absurdo sostener que la secesión no implica o significa cambio constitucional alguno.

Desde esta perspectiva, las secesiones pactadas no supondrían por ello la destrucción de las Constituciones respectivas de los Estados matrices sino que deberían abordarse como reformas de aquellas. Sin llegar a tanto, el Tribunal Constitucional de España apunta la posibilidad de encauzar las demandas secesionistas a través de la reforma constitucional ${ }^{21}$.

18 López Basaguren, A.: «Escocia y el referéndum por la independencia: algunas enseñanzas» en Cuadernos de Alzate, n. ${ }^{\circ}$ 46-47, 2013, pp. 127-141.

19 Revista Española de Derecho Internacional, Vol. 63, n. ${ }^{\circ}$ 1, 2011; Urbiola López de MonTENEGRO, J.: El proceso de independencia de Kosovo Su incidencia en el principio de soberanía e integridad territorial del Estado, CEPC. Madrid, 2013.

20 Toda secesión supone una modificación (reducción) del ámbito de aplicación personal y territorial de la Constitución. La Constitución deja de aplicarse en un territorio y una parte de la población (la que habita el territorio que se independiza) deja de estar sujeta a la misma.

21 STC 42/2014, de 25 de marzo. Fondevila, M.: «Derecho a decidir y soberanía. A propósito de la STC 42/2014» en Teoría y Realidad Constitucional, n. ${ }^{\circ} 34,2014$, pp. 587-606. Fossas EsPaLder, E.: Interpretar la política. Comentario a la STC 42/2014, de 25 de marzo, sobre Declaración de soberanía y el derecho a decidir del pueblo de Cataluña» en Revista Española de Derecho Constitucional, n. ${ }^{\circ} 101$, 2014, pp. 273300 . 


\section{Secesión y reforma constitucional}

Sea de ello lo que fuere, la respuesta a esta cuestión dependerá de la posición que se mantenga sobre la existencia o no de límites materiales (y no sólo formales) al poder de reforma. La secesión pactada sólo es concebible como proceso jurídico (no meramente fáctico) si se admite la posibilidad de que a través del procedimiento de reforma constitucional se incluya en la Constitución una cláusula de secesión. Un sector de la doctrina y el Tribunal Constitucional defienden esa tesis. Se apoyan en que la Constitución de 1978 carece de cláusulas de intangibilidad, y en el rechazo a la teoría de los límites materiales implícitos a la reforma constitucional defendida por autores tan relevantes como Schmitt, Lucas Verdú o De Vega.

A nuestro juicio, esa comprensión del poder de reforma como un poder materialmente ilimitado impide diferenciar jurídicamente al poder constituyente del poder de reforma. Y sin esa distinción la idea misma de Constitución normativa deja de tener sentido. El concepto de Constitución normativa nos obliga a configurar al Poder de reforma como un poder constituido y, por ello, limitado no sólo procedimentalmente sino también materialmente. Y ello con independencia de que dichos límites hayan sido expresamente dispuestos por el constituyente en las denominadas cláusulas de intangibilidad. Como ha escrito Pedro de Vega en una obra ya clásica, y difícilmente superable, sobre este tema: «Si el principio jurídico de supremacía constitucional impone el reconocimiento de unos límites implícitos formales que se centran, básicamente, en las propias normas reguladoras del procedimiento de reforma, el principio político de soberanía popular condicionará, por su parte, la obligada aparición de unos límites implícitos materiales, cuya fundamentación y desarrollo han de ser deducidos, desde la lógica de la legitimidad, como necesario correlato de los valores materiales y los supuestos políticos en que se inspira y se vertebra el moderno Estado constitucional» ${ }^{22}$.

En este sentido, no merece la pena discutir sobre si los principios y los valores legitimadores del ordenamiento constitucional forman parte o no de la realidad jurídica y tienen, por tanto, un valor normativo o no, en la medida en que, con frecuencia, y así ha ocurrido en el caso español, dichos principios y valores han sido expresamente recogidos por el constituyente (arts. 1 y 10). Por ello, lo que importa es subrayar que «lo que resulta incuestionable es que, bien cuando aparecen como elementos claramente definidos en los textos constitucionales o en los preámbulos de los mismos, o bien cuando se presentan como supuestos indiscutibles de la ideología social imperante, esos principios y valores legitimadores

22 De Vega, P.: La reforma constitucional y la problemática del Poder Constituyente, Tecnos, Madrid, 1991, pp. 283-284. En este sentido, revisten también gran interés, las reflexiones del profesor Ruipérez que se sitúan en la senda marcada por su maestro el profesor De Vega: Ruiperez, J.: «Algunas consideraciones sobre la reforma constitucional» en Revista de Estudios Políticos, n. ${ }^{\circ}$ 75, 1992, pp. 233-258. 
del ordenamiento, tendrán por fuerza que configurarse como zonas exentas al poder de revisión, y adquirir, por tanto, el indudable carácter de límites materiales implícitos a todo poder de reforma ${ }^{23}$.

Entender que el artículo 168 otorga al poder de reforma la facultad de modificar totalmente el ordenamiento conduce a consagrar un despropósito que jurídicamente repugna a la lógica global del Estado Constitucional ${ }^{24}$. Por ello dicho precepto, en el marco de una Constitución normativa, sólo puede ser interpretado en el sentido de que el poder de reforma puede alterar toda la literalidad de la Constitución siempre y cuando respete los mencionados principios y valores legitimadores del Estado Constitucional en general ${ }^{25}$, y los de la fórmula política del Estado español, en particular.

Con estas premisas, entendemos que el principio democrático según el cual la soberanía reside en el pueblo, se configura como un límite material implícito a la reforma constitucional. Por lo que se refiere a la Constitución española, es el artículo 1.2 el que contiene el principio democrático de la soberanía popular. La supresión del mismo ha escrito el profesor Pedro de Vega, no podría interpretarse como una operación de revisión, «sino como un acto revolucionario de destrucción de la Constitución existente» ${ }^{26}$.

Por otro lado, y a mayor abundamiento, conviene recordar siguiendo también a De Vega que tres son los aspectos o dimensiones que la Reforma Constitucional presenta: a) en primer lugar es un instrumento para adecuar la realidad jurídica a la realidad política; b) en segundo lugar es un mecanismo para articular la continuidad histórica del Estado, c) y, finalmente, en tercer lugar es una institución básica de garantía ${ }^{27}$. Porque esto es así no hace falta demasiada agudeza

23 De Vega, P.: La reforma constitucional...ob. cit, p. 285. En el mismo sentido se pronuncia el profesor Balaguer, uno de los más cualificados estudiosos de nuestro sistema de fuentes: «Existen límites materiales a la reforma que se derivan de la interdicción de desnaturalizar el orden constitucional vigente. La falta de explicitación de los mismos no impide su eficacia jurídica que se manifiesta en la imposibilidad de aceptar, bajo el régimen constitucional vigente y desde una perspectiva jurídica, determinadas reformas que desfiguren el núcleo esencial de la Constitución». Balaguer, F.: Fuentes del Derecho, Tecnos, Madrid, 1992. Vol. II, p. 39.

24 Una aproximación a este problema desde la óptica del derecho comparado en RAGONE, S.: El control judicial de la reforma constitucional. Aspectos teóricos y comparativos, México, Porrúa, 2012.

25 Existen unos límites materiales implícitos que operan en el seno de todo Estado Constitucional y son comunes, por tanto, a todos los ordenamientos. Dichos límites vienen configurados por los tres principios esenciales e inherentes a esta forma histórica de Estado: el primero de ellos, es el principio democrático según el cual la soberanía reside en el pueblo, titular indiscutido e indiscutible del poder constituyente; los otros dos encuentran su fundamento en aquél, y son el principio político liberal que se manifiesta en la garantía de la libertad mediante el reconocimiento de los derechos y las libertades fundamentales de los individuos y en la organización del Estado conforme al principio de separación de poderes; y el principio jurídico de supremacía constitucional, que se traduce en la existencia de un procedimiento específico de reforma y de control de constitucionalidad de las normas.

26 De VegA, P.: La reforma, ob. cit., p. 286.

27 DE VEGA, P.: La reforma constitucional, ob. cit., p. 67. «Si frente al poder constituyente y soberano, el poder de reforma aparece como mecanismo de articulación de la continuidad jurídica del Estado, frente al resto de los poderes constituidos se presenta como la institución básica de garantía», p. 69. 
para concluir que si la reforma sirve para articular la continuidad del Estado que es tanto como para preservar la continuidad del Constituyente para lo que nunca podrá ser utilizada es para la destrucción del Estado y del Constituyente. Este acto revestirá por fuerza, siempre, la naturaleza de un acto revolucionario ${ }^{28}$. En definitiva y, como lúcidamente ha subrayado el profesor Ruipérez «el reconocimiento del ius secessionis (exigiría) que hiciese su entrada en escena un nuevo Constituyente como poder revolucionario, fáctico, político-existencial, absoluto, soberano e ilimitado en el contenido de su voluntad que es, en definitiva, el único sujeto que puede realizar la hipótesis de lo que Carl Schmitt denominó 'cambio de constitución'29 o en su caso proceder a la aprobación de un nuevo Texto Constitucional» ${ }^{30}$.

Las denominadas «secesiones pactadas» no tienen cabida en el Estado Constitucional en general $^{31}$, y en el nuestro, en particular. Los procedimientos de reforma constitucional no son aptos tampoco para incluir cláusulas y procedimientos que conduzcan a la secesión. Únicamente el Poder Constituyente podría —en teoría - incluir una de estas clausulas pero con ello renunciaría a cumplir con su función básica: constituir un Estado, puesto que lo que estaría alumbrando es una comunidad política meramente provisional.

En España, el procedimiento de reforma constitucional previsto en el artículo 168 tampoco permite incluir en la Constitución una hipotética cláusula de secesión. Esta sólo podría establecerse en el supuesto de que se abriera un nuevo proceso constituyente para elaborar y aprobar un nuevo Texto Constitucional que reemplazara al vigente.

En definitiva, de la misma forma que el Derecho Internacional consagra el derecho a la integridad territorial de los Estados que, como España, cuentan con gobiernos representativos «de la totalidad del pueblo perteneciente al territorio», y se opone por tanto a cualquier pretensión secesionista, el Derecho Constitucional impide también incluir el derecho de secesión en el ordenamiento interno.

Precisado así el significado y alcance de la secesión, en el Derecho Internacional y en el Derecho Constitucional, vamos a examinar sus implicaciones en el marco de la Unión Europea. Para ello vamos a ver como se aborda el fenómeno de

28 Dicho con otras palabras, la reforma podrá afectar al acto constitucional pero para lo que no podrá nunca ser utilizada es para la destrucción o transformación del pacto social. Me remito a TAJADURA, J.: «El pacto social como límite a la reforma del acto constitucional» en (Roura, S., y Tajadura, dirs) La Reforma Constitucional, Biblioteca Nueva, Madrid, 2005.

29 Sснміт, C.: Teoría de la Constitución, ob. cit., pp. 115 y ss.

30 Ruipérez, J.: Proceso Constituyente, Soberanía y Autodeterminación, Biblioteca Nueva, Madrid, 2003 , p. 321

31 Los casos británico y canadiense se configuran como excepciones que sólo tienen sentido en el marco de un constitucionalismo flexible, en el que la vigencia del principio de soberanía parlamentaria permite eludir el problema de la reforma constitucional. Y aun ese marco resulta discutible puesto que una cosa es que el Parlamento de Westminster sea soberano y otra muy distinta que pueda disponer libremente de esa soberanía.

UNED. Teoría y Realidad Constitucional, núm. 37, 2016, pp. 347-379 
la secesión en el Derecho europeo. Esto nos obliga a examinar dos tipos de problemas: por un lado, el de la secesión de un Estado miembro respecto de la propia Unión (3); por otro, el de la eventual fragmentación de un Estado miembro por la secesión de una parte de su territorio (4).

\section{LA RETIRADA DE UN ESTADO DE LA UNIÓN EUROPEA (SECESIÓN PACTADA).}

\section{La «indeterminación institucional» de la Unión Europea}

Europa se presenta ante el jurista como una organización de Estados, cuya verdadera naturaleza jurídica resulta difícil de determinar. En todo caso, lo que resulta indiscutible es que dicha organización se inspira y se vertebra sobre los valores y principios del federalismo. La Unión Europea presenta numerosos rasgos propios de un esquema federal de articulación del poder: las instituciones comunitarias ejercen directamente potestades normativas y jurisdiccionales sobre los particulares; existe un orden de distribución de competencias entre la Unión y los Estados miembros; los mecanismos de resolución de conflictos encajan también en el esquema federal. Admitido esto, el problema surge cuando se trata de determinar a cuál de las manifestaciones estructurales históricas de éste se adscribe la nueva comunidad política europea. Y ello porque la Unión Europea tal y como está actualmente configurada por el Tratado de Lisboa, no responde de manera total, plena y absoluta ni al concepto clásico del Estado Federal ni al de Confederación de Estados. La Unión Europea presenta rasgos y elementos de uno y de otra.

Entre los grandes teóricos del federalismo, Georg Meyer fue quien formuló la distinción entre las dos manifestaciones del fenómeno federal de la forma más tenue y menos intensa habida cuenta que, según él, la celebración del Tratado por el que se crea la Confederación de Estados, supone ya la renuncia por parte de sus integrantes a su status de Estados soberanos e independientes, sujetos del Derecho Internacional, en beneficio de la nueva entidad política. Confederación y Estado Federal quedan así, aparentemente, equiparados. Y digo, aparentemente, porque para G. Meyer entre una y otro existen dos diferencias fundamentales. En primer lugar, el procedimiento en virtud del cual puede verificarse la reforma de su norma fundacional, es diferente según nos encontremos en un Estado Federal o en una Confederación. Mientras que en la Confederación la reforma de su texto fundamental requiere, con carácter general, la unanimidad de los miembros, en el caso del Estado Federal, es suficiente con que el proyecto de revisión sea aprobado por una mayoría cualificada. Y, en segundo lugar, diferentes son también los efectos que las normas jurídicas emanadas de los órganos centrales producen sobre los ciudadanos según nos encontremos en un Estado Federal o en una Confederación. En el Estado Federal, las normas jurídicas de la Federación son direc- 
tamente aplicables a todos los ciudadanos y no necesitan de ninguna convalidación por parte de las autoridades de las colectividades miembros. En la Confederación, por el contrario, las normas confederales sólo pueden ser aplicadas a los ciudadanos en la medida en que han sido transformadas en derecho interno por las autoridades de las colectividades miembros.

Atendiendo a la primera diferencia, la Unión Europea en la medida en que sus normas fundacionales deben ser siempre reformadas por unanimidad, se situaría en la órbita de la Confederación de Estados. Pero si nos atenemos a la segunda de las diferencias acuñadas por la clásica Teoría del Estado, la Unión Europea dada la aplicación preferente y directa de sus normas en el seno de los Estados miembros estaría mucho más próxima a la forma de Estado Federal.

Son las anteriores consideraciones las que nos llevan a compartir la tesis del profesor La Pérgola, en el sentido de afirmar la necesidad de reformular las categorías clásicas sobre el federalismo de la Teoría del Estado. De lo que se trataría es de diferenciar, dentro de la Confederación, entre una forma antigua o arcaica y una forma moderna ${ }^{32}$. A la primera responderían los modelos históricos por todos conocidos: la Unión de las trece antiguas colonias americanas desde el 5 de noviembre de 1779 hasta la puesta en marcha de la Convención de Filadelfia; la Confederación Helvética desde 1803 a 1848; o la situación de los Lánder alemanes hasta la creación del Imperio guillermino y la aprobación de la Constitución de 1871. A la segunda opción se adscribiría la Unión Europea. Su principal característica sería la de que no siendo aún un Estado Constitucional en su manifestación de Estado Federal, se encuentra mucho más centralizado de lo que lo estuvieron las Confederaciones históricas.

Desde esta óptica, aunque la Unión no tiene una Constitución, puesto que su existencia se fundamenta en un Tratado Internacional, el Tratado de Lisboa, es cierto que encontramos en ella en tanto que Comunidad de Derecho, una serie de elementos: declaración de derechos, división de poderes (horizontal y vertical), principio de primacía del derecho europeo, que pueden identificarse con los principios cuya convergencia dio lugar a finales del siglo XviII a las primeras Constituciones en sentido moderno ${ }^{33}$. Tanto el principio político liberal (art. 16 de la Declaración francesa de Derechos del Hombre) como el principio jurídico de supremacía constitucional (principio de primacía de los Tratados y del derecho europeo sobre el derecho nacional) se encuentran recogidos en el Tratado de Lis-

32 Ruipérez, J.: La Constitución europea y la teoría del Poder Constituyente, Biblioteca Nueva, Madrid, 2000. Sobre la indeterminación institucional, De Miguel, J.: El gobierno de la economía en la Constitución europea. Crisis e indeterminación institucional, Bosch Editor, Barcelona, 2011.

33 Sobre la naturaleza constitucional del ordenamiento jurídico comunitario articulado a través de la conexión formal y material entre Tratados originarios y Constituciones nacionales: Pernice, I.: «Derecho constitucional europeo y Derecho constitucional de los Estados miembros» en Civitas. Revista Española de Derecho Europeo, n. ${ }^{\circ}$ 8, 2003, pp. 602 y ss.; Cruz Villalón, P.: La Constitución inédita. Estudios ante la constitucionalización de Europa, Trotta, Madrid, 2004. 
boa. Este, a diferencia de un Tratado Internacional clásico se fundamenta en una doble legitimidad: la de los Estados y la de los ciudadanos, que es la que explica y otorga sentido, unidad y coherencia al proceso de integración europea.

Hasta la aprobación del Tratado de Lisboa, el Derecho comunitario no contenía previsión alguna sobre la posibilidad de que un Estado miembro abandonase la Unión. En ese contexto, y teniendo en cuenta la doctrina establecida por el TJUE en la Sentencia Costa vs Enel (1964) según la cuál el proyecto de integración continental implicaba una «Comunidad de Derecho de duración ilimitada», los más federalistas entendieron que los Estados carecían de un derecho de secesión que pudieran ejercer de forma unilateral. Esta interpretación se veía reforzada por lo previsto en los artículos 54 y 56 del Convenio de Viena sobre el derecho de los tratados de 1969 que dispone que la retirada de un Estado de una organización internacional solo es posible cuando lo prevea el propio tratado, medie el consentimiento de las partes, y en ausencia de estos requisitos, sea conforme a la finalidad del propio tratado o pueda vislumbrarse claramente la intención de las partes de admitir esa posibilidad.

En el caso de los Tratados comunitarios, estos no preveían ninguna cláusula específica que permitiera y regulara el modo de abandonar la Unión. La necesidad de que medie el consentimiento de las partes supone la negación de la secesión como derecho que pueda ejercerse unilateralmente. Por otro lado, si la finalidad de las Comunidades es alcanzar una Unión política, está claro que ese fin es incompatible con la cláusula de secesión. Y finalmente, no resulta en modo alguno fácil deducir de los Tratados y de sus antecedentes, que fuera intención de los Estados fundadores admitir esa posibilidad. Por todo lo anterior podía afirmarse que en la Unión Europea no existía un derecho de secesión de los Estados miembros que estos pudieran ejercer de forma incondicionada y unilateral ${ }^{34}$.

Ahora bien, esa interpretación en clave constitucional y federal de los tratados distaba mucho de ser mayoritaria. Gran parte de la doctrina sostenía que la falta de previsión de un procedimiento de retirada en los tratados no era argumento suficiente para impedir a un Estado ejercer su facultad de abandonar la Unión ${ }^{35}$. El derecho de secesión entendido como posibilidad de abandonar unilateralmente la Unión era deducido del principio de soberanía. Los Estados miembros continuaban siendo soberanos y por tanto no habían renunciado a su poder de decisión sobre su continuidad en la Unión.

El Tratado de Lisboa puso fin a esta controversia e incluyó el derecho de los Estados miembros a abandonar la Unión. Fue una gran victoria de los soberanistas frente a los federalistas ${ }^{36}$. Y no fue la única. No es este el lugar para poner de

34 Diez-Picazo, L.M.: Constitucionalismo en la Unión Europea, Civitas, Madrid, 2002, pp. 128 y ss.

35 Friel R. J.: «Secession From the European Union: Checking Out of the Proverbial "Cockroach Motel'», Fordham International Law Journal, Vol. 27, n. ${ }^{\circ} 2,2003$, pp. 590-641.

36 Remito a mi monografía TAjadura, J.: El futuro de Europa: luces y sombras del Tratado de Lisboa, Comares, Granada, 2010 
manifiesto las diferencias existentes entre el Tratado de Lisboa y el Tratado Constitucional - frustrado por los resultados negativos de los referendos celebrados en Francia y en Holanda- pero sí el de examinar el verdadero significado y alcance de la cláusula de secesión.

\section{El derecho de retirada (art. 50 TUE)}

El artículo 50 del TUE no contiene un derecho de secesión que pueda ser ejercido de forma incondicionada y unilateral. Si bien es cierto que permite a los Estados miembros abandonar la Unión, no lo es menos que les fija ciertas condiciones y límites ${ }^{37}$.

En un principio, parece que la cláusula que nos ocupa establece un derecho unilateral de salida de la UE dado que faculta al Estado para notificar (y no solicitar) al Consejo Europeo su voluntad de cesar en su condición de Estado miembro. Sin embargo, el efecto jurídico que el Tratado atribuye a esa notificación no es que el Estado notificante deje de pertenecer a la Unión. La notificación abre un proceso de negociación de la retirada lo que pone de manifiesto que esta no se contempla ni como unilateral ni como inmediata. El apartado segundo del artículo 50 establece la necesidad de formalizar un acuerdo entre la Unión y el Estado miembro de que se trate, a través de la mayoría cualificada del Consejo de Ministros y con arreglo al artículo 218. 3 TFUE, para determinar la forma de su retirada, y el marco jurídico que regulará sus relaciones futuras con la Unión.

El abandono de la Unión se produce y tiene efecto en el momento de la entrada en vigor del acuerdo que comentamos. Ahora bien, en el supuesto de que no fuera posible alcanzar ese acuerdo, la retirada tendría efectos a los dos años a contar desde el día en que se notificó la voluntad de abandonar la Unión. Al tratarse en este último supuesto de una retirada no pactada, las relaciones de la Unión con el antiguo Estado miembro quedarían sin regular, y cabe prever que

37 «1. Todo Estado miembro podrá decidir, de conformidad con sus normas constitucionales, retirarse de la Unión. 2. El Estado miembro que decida retirarse notificará su intención al Consejo Europeo. A la luz de las orientaciones del Consejo Europeo, la Unión negociará y celebrará con ese Estado un acuerdo que establecerá la forma de su retirada, teniendo en cuenta el marco de sus relaciones futuras con la Unión. Este acuerdo se negociará con arreglo al apartado 3 del artículo 218 del Tratado de Funcionamiento de la Unión Europea. El Consejo lo celebrará en nombre de la Unión por mayoría cualificada, previa aprobación del Parlamento Europeo. 3. Los Tratados dejarán de aplicarse al Estado de que se trate a partir de la fecha de entrada en vigor del acuerdo de retirada o, en su defecto, a los dos años de la notificación a que se refiere el apartado 2, salvo si el Consejo Europeo, de acuerdo con dicho Estado, decide por unanimidad prorrogar dicho plazo. 4. A efectos de los apartados 2 y 3, el miembro del Consejo Europeo y del Consejo que represente al Estado miembro que se retire no participará ni en las deliberaciones ni en las decisiones del Consejo Europeo o del Consejo que le afecten. La mayoría cualificada se definirá de conformidad con la letra b) del apartado 3 del artículo 238 del Tratado de Funcionamiento de la Unión Europea. 5. Si el Estado miembro que se ha retirado de la Unión solicita de nuevo la adhesión, su solicitud se someterá al procedimiento establecido en el artículo 49». 
fueran, en muchos sentidos, conflictivas. Se trata de un situación que sí jurídicamente es posible, políticamente debería evitarse.

En definitiva, la secesión está prevista en la Unión Europea, pero no está regulada como un derecho de ejercicio unilateral. Al contrario, el TUE contempla un procedimiento de negociación entre la Unión y el Estado en cuestión que en principio debe plasmarse en un acuerdo. Ahora bien, ciertamente y en el supuesto de que el acuerdo no sea posible, proporciona al Estado una base jurídica para abandonar la Unión.

Naturalmente, se trata de una base jurídica que resulta manifiestamente incompatible con los fines de la Unión: «profundizar en una unión más estrecha entre los pueblos de Europa». Evidente resulta que permitir a un Estado miembro abandonar la Unión supone aceptar un retroceso en ese proceso y lejos de estrechar, solo sirve para distanciar al Estado de que se trate de la Unión política. La incompatibilidad del artículo 50 con los fines del Tratado es evidente, pero es consecuencia de la contradicción última que subyace en todo el proceso de integración y que solo podrá ser resuelta cuando la Unión se transforme en una auténtica Unión política en sentido constitucional y federal ${ }^{38}$.

Lo que ahora interesa - a los efectos de este estudio - es recordar los efectos de la salida. Y ello porque son los mismos que tendría el supuesto de que no fuera un Estado sino una parte del mismo - en nuestro caso, la Comunidad Autónoma de Cataluña - la que llevara a cabo la salida. Cualquier Estado que utilice la cláusula de retirada del artículo 50 y desee en el futuro volver a incorporarse a la UE tendrá que someterse al procedimiento de adhesión ordinario previsto en el artículo 49 TUE (art. 50.5 TUE).

En el marco de la Unión Europea, por tanto, no cabe la secesión unilateral. Esta es siempre pactada. Si un Estado no puede abandonar unilateralmente la Unión, es evidente que — con arreglo al Derecho europeo- tampoco puede hacerlo una parte de un Estado miembro, esto es, una región o Comunidad Autónoma. Desde esta óptica, la secesión unilateral de una parte del territorio de un Estado miembro sería contraria al Derecho europeo (y no sólo al Internacional General y al Constitucional interno).

El caso de las secesiones pactadas es diferente. El Derecho europeo admite la secesión pactada de un Estado miembro respecto de la Unión. Por ello podría admitir también una secesión pactada en el interior de un Estado miembro. Pero se trata de un supuesto respecto al que las instituciones europeas no pue-

38 «La UE no es un Estado ni ha surgido de una única voluntad constituyente, lo que propicia que el actual momento del proceso de integración pueda ser caracterizado como de indeterminación institucional. Ello significa que en la larga transición hacia la Federación europea, los Estados miembros que componen la Unión se han ido debilitando, pero la soberanía europea no se ha democratizado y reforzado en términos supranacionales, lo que está otorgando indudables oportunidades a separatismos que se han hecho fuertes en las parcelas de poder otorgadas por las diferentes formas de descentralización política», DE MigUEL, J.: La cuestión de la secesión..., ob. cit., p. 213. 
den quedar al margen. Y ello porque la ruptura de un Estado miembro no puede considerarse nunca como un asunto meramente interno y ajeno a la Unión Europea. Como ha advertido De Miguel, «cualquier nuevo Estado que se cree en el seno de la Unión, deberá contar con el amparo o el consentimiento de las instituciones comunitarias y los Estados miembros que la conforman, tanto en lo relativo a su necesario abandono como posterior incorporación al proyecto de integración» ${ }^{39}$.

La ruptura de un Estado miembro supone una alteración (por reducción) de su territorio, y este se configura como el ámbito de aplicación espacial del derecho europeo ${ }^{40}$. Por ello, a quienes sostienen que los Estados miembros pueden disponer libremente sobre su territorio hay que recordarles que el derecho europeo y la praxis conducen a defender lo contrario.

\section{El territorio de los Estados miembros y la Unión Europea}

La doctrina mayoritaria entiende que el territorio es uno de los elementos objetivos de los Estados miembros y que estos — en cuanto soberanos- pueden decidir libremente sobre él. Desde esta óptica, las posibles modificaciones territoriales de los Estados miembros — como la que pudiera derivarse para España de la secesión de Cataluña - serían un asunto interno de los Estados miembros.

En nuestra opinión, y por las razones que vamos a exponer, las posibles alteraciones territoriales de los Estados miembros son un asunto de capital importancia para la UE. El territorio de los Estados es el ámbito de aplicación espacial del Derecho europeo, y de las políticas comunes. El territorio es la base sobre la que se desarrolla el mercado único y el espacio europeo de libertad y justicia. Cualquier alteración del territorio de un Estado miembro afecta de forma directa e inmediata a la Unión Europea ${ }^{41}$.

Conviene recordar cuál ha sido la práctica comunitaria en aquellos casos en los que los Estados han alterado el ámbito de aplicación territorial del Derecho comunitario. En este sentido es preciso distinguir dos tipos de supuestos. En primer lugar, aquellos en los que un Estado miembro altera el ámbito de aplicación de los Tratados, excluyendo del mismo por su voluntad unilateral, territorios que permanecen bajo su soberanía. En este primer grupo de casos se requiere una acción normativa de la UE, a través del artículo 355.6 TFUE para determinar

39 De Miguel, J.: La cuestión de la secesión..., ob. cit., p. 214.

40 La secesión de una región no sólo ha de encontrar reconocimiento dentro de la Constitución nacional, si ello fuera posible, sino en el marco de los Tratados de la UE, pues supone una alteración formal de la dimensión territorial de la aplicación del derecho europeo y una disminución de la comunidad política supranacional forjada a través del artículo 49 TUE.

41 Martín y Pérez de Nanclares, J.: El federalismo supranacional: ¿un nuevo modelo para la Unión Europea?, Consejo Vasco del Movimiento Europeo, Bilbao, 2003. 
las relaciones jurídicas entre la UE y el territorio excluido ${ }^{42}$. En segundo lugar, nos encontramos con los supuestos en los que, o bien un Estado miembro adquiere territorios de otro Estado miembro, o bien un Estado miembro aumenta su propio territorio. En este segundo grupo de casos no se precisa ninguna acción normativa de la UE y se aplica simplemente el principio de continuidad del Estado matriz (art. 52 TUE) ${ }^{43}$.

a) Los denominados «territorios de ultramar» constituyen el primer caso de exclusión de territorios nacionales del derecho de la Unión. En la cuarta parte del TFUE se establece que los Estados miembros convienen en asociar a la UE los países y territorios que mantienen relaciones especiales con Dinamarca, Francia, Países Bajos y Reino Unido. La asociación tendrá como finalidad «contribuir a favorecer los intereses de los habitantes de dichos países y territorios a su prosperidad, de modo que puedan alcanzar el desarrollo económico, social y cultural». El artículo 203 TFUE regula el procedimiento institucional para concretar los términos de la asociación.

Cuando los Estados mencionados modifican su relación con estos territorios de ultramar y como consecuencia de ello se reduce el ámbito de aplicación del Derecho comunitario, se aplica el ya citado artículo 355.6 TFUE. Este precepto sirve para articular la nueva relación entre los territorios de ultramar y la Unión mediante una decisión unánime del Consejo Europeo previa consulta a la Comisión. Cuando dichos territorios logran la independencia de la metrópoli, sus relaciones con la UE se rigen por convenios de asociación temporal con ella. En estos convenios pueden ser parte incluso países que no formaron parte con anterioridad de ningún Estado miembro. Actualmente, el marco normativo que articula estas relaciones es el configurado por el Acuerdo de Asociación con los Países de África, el Caribe y el Pacífico, firmado en Cotonou (Benín) en el año 2000 con un periodo de vigencia de 20 años.

La finalidad de estos acuerdos especiales de Asociación es permitir que los antiguos territorios sobre los que se aplicaba el Derecho comunitario puedan seguir beneficiándose de los efectos positivos del proceso de integración sin necesidad de ser miembros de pleno derecho de la UE. Al mismo tiempo, la UE conserva de esta forma las ventajas derivadas de esta especial relación con esos territorios.

42 Artículo 355. 6 TFUE: «El Consejo Europeo, por iniciativa del Estado miembro de que se trate, podrá adoptar una decisión que modifique el estatuto respecto de la Unión de alguno de los países o territorios daneses, franceses o neerlandeses a que se refieren los apartados 1 y 2. El Consejo Europeo se pronunciará por unanimidad, previa consulta a la Comisión».

43 Mangas Martín, A.: «La secesión de territorios en un Estado miembro: efectos para el derecho de la UE» en Revista de Derecho de la Unión Europea, n. ${ }^{\circ}$ 25, 2013, p. 54. 
En todo caso, los países y territorios de ultramar que se independizan de sus respectivas metrópolis, al convertirse en Estados independientes dejan de formar parte de la Unión Europea como tal y pierden el conjunto de los beneficios directos que se derivan de esa pertenencia ${ }^{44}$.

b) El caso de Groenlandia es similar a los que comentamos ${ }^{45}$. Confirma que un Estado no puede unilateralmente reducir el ámbito de aplicación del Derecho europeo. Este no se aplica en Groenlandia, pero no por la voluntad unilateral del Estado danés sino en virtud de un Tratado celebrado en 1984 entre Dinamarca y la UE. El Tratado faculta a Dinamarca a dejar de aplicar el derecho comunitario en una parte de su territorio (Groenlandia) que sin embargo permanece bajo su soberanía territorial, si bien con cierto grado de autonomía. Veinte años después el Consejo de la UE concluyó otro acuerdo con Dinamarca para establecer una asociación especial con Groenlandia en materia de pesca.

c) Finalmente, el único caso de secesión unilateral en la historia del proceso de integración europea es el que se produjo con la independencia de Argelia. La independencia de Argelia respecto de Francia supuso una reducción del ámbito de aplicación espacial del derecho comunitario. Argelia se constituyó como un nuevo Estado, ajeno a la UE, y sus ciudadanos, empresas y poderes públicos quedaron desvinculados del derecho comunitario. Se trató de un supuesto de sucesión de Estados por la vía fáctica en la que la modificación territorial operada fue aceptada tácitamente por el resto de Estados miembros y por la propia UE. En todo caso, tras la independencia del antiguo territorio de ultramar se mantuvo transitoriamente el régimen previsto en el antiguo artículo 227.2 TCE sobre las disposiciones del Tratado aplicables a Argelia y otros territorios de ultramar ${ }^{46}$.

Como puede verse, todos los casos examinados, por un lado, se refieren a territorios situados geográficamente fuera de Europa y, por otro, — dejando a salvo Groenlandia - se enmarcan en el contexto de aplicación del principio de autodeterminación de los pueblos.

El segundo tipo de supuestos es el de aquellas modificaciones territoriales de los Estados miembros que no reducen el ámbito de aplicación espacial del derecho comunitario y, por lo tanto, no inciden de forma negativa en él. En la historia

44 Medina, M.: El derecho de secesión en la Unión Europea, Marcial Pons. Fundación Alfonso Martín Escudero, Madrid, 2014, p. 76. Sus nacionales pierden todas las ventajas derivadas del estatuto de la ciudadanía europea, salvo los que expresamente la conserven si el Estado metropolitano ha decidido mantener formas de doble nacionalidad.

45 WeERTs, J.: «L'évolution du droit de retrait de l’Union européenne et sa résonance sur l'intégration européenne», Cahiers de Droit européen, n. ${ }^{\circ}$ 2, 2012.

46 Ortega, A. y De Areilza, J. M.: «Escisión y permanencia en la UE. Aproximación a un marco teórico sin precedentes» en Claves de Razón práctica, n. ${ }^{\circ} 100,2000$. 
de la UE se han dado dos: un traspaso de territorios y una ampliación territorial de un Estado miembro. Ambos tuvieron como uno de sus protagonistas a la República Federal de Alemania.

En 1957 la región del Sarre, bajo soberanía francesa, pasó a formar parte de la República Federal de Alemania. En la medida en que tanto Francia como Alemania eran Estados miembros de las Comunidades Europeas, el traspaso territorial no alteró el ámbito de aplicación espacial del derecho comunitario. Únicamente trasladó la responsabilidad por su cumplimiento en el territorio afectado (El Sarre) de Francia a Alemania.

Finalmente, en 1990, el territorio de la UE se vio incrementado como consecuencia de la ampliación territorial de Alemania verificada como consecuencia de la incorporación de los Lander de la República Democrática Alemana a la República Federal. La forma de llevar a cabo la reunificación estuvo condicionada por el Derecho europeo. Como es sabido, la Ley Fundamental de Bonn contemplaba dos fórmulas distintas para el caso. Por un lado, el antiguo artículo 23 permitía su aplicación a «otras partes de Alemania». Por otro, el antiguo artículo 146 preveía la posibilidad de aprobar tras la reunificación una nueva Constitución. Esta última opción fue descartada puesto que ponía en cuestión la continuidad jurídica de la RFA, al implicar el surgimiento de un nuevo sujeto de derecho internacional. Por el contrario, la disolución y extinción de la RDA, permitió la inclusión de su territorio y población en una RFA sin poner en cuestión su continuidad como sujeto de derecho internacional, y por lo que a nosotros importa, como Estado miembro de la $\mathrm{UE}^{47}$. «Al no aparecer un nuevo Estado — subraya De Miguel- Alemania no tuvo que pedir su reingreso, simplemente notificó a la UE y a los países terceros que se hacía cargo de los derechos y obligaciones del Estado extinguido, no teniendo ello consecuencias para el derecho comunitario ${ }^{48}$. La ausencia en este caso de una intervención formal por parte de la UE se debió al hecho de que el ámbito de aplicación espacial del derecho comunitario no se vio reducido. Se vio acrecentado pero no como consecuencia de la ampliación de la comunidad política propiamente europea que no incrementó el número de Estados miembros, sino por la ampliación de la comunidad política alemana que integró a la población y al territorio de la extinta RDA.

Recapitulando lo expuesto en este epígrafe podemos realizar estas dos afirmaciones:

a) El Derecho europeo no contiene una cláusula de secesión entendido como un derecho que pueda ser ejercido de forma incondicionada y unilateral por los Estados miembros.

47 Arnold, R.: La unificación alemana. Estudios sobre derecho alemán y europeo. Civitas, Madrid, 1993. Jacque, J.P.: «L'unification de l'Allemagne et la Communauté Européeene» en Revue Générale de Droit International Public», Vol. 94, n. ${ }^{\circ} 4,1990$.

48 De Miguel, J.: «La cuestión de la secesión en la UE: una visión constitucional» en Revista de Estudios Políticos, n. ${ }^{\circ} 165,2014$, p. 227. 
b) El Derecho europeo no faculta a los Estados a disponer libremente de su territorio, de forma que el ámbito de aplicación espacial del derecho comunitario pueda ser modificado por estos de forma unilateral.

Este es el marco normativo - europeo- con el que debe confrontarse la posible secesión de Cataluña —o cualquier otra región europea — respecto a España - o cualquier otro Estado miembro-.

La secesión unilateral de una parte del territorio de un Estado miembro nunca podría ser reconocida por los demás Estados y por la propia Unión puesto que dicho reconocimiento es incompatible con el respeto al principio de integridad territorial de los Estados miembros, y sería contrario al principio de lealtad o de cooperación entre los Estados miembros entre sí, y entre estos y la Unión. Por tanto, el problema surge, una vez más, al enfrentarnos a la hipótesis de las secesiones pactadas. ¿Tiene cabida en el ordenamiento comunitario europeo la secesión pactada o consensuada de una parte de un Estado miembro? ¿Qué consecuencias jurídicas se derivarían de una tal secesión?.

\section{LA OBLIGACIÓN DE LOS ESTADOS MIEMBROS DE MANTENER SU INTEGRIDAD TERRITORIAL.}

Los responsables políticos de la Unión Europea — y singularmente, la Comisión- se han limitado a recordar que los nuevos Estados surgidos de un proceso de secesión territorial respecto a un Estado miembro (sea Escocia respecto el Reino Unido, Cataluña respecto a España, o cualquier otro) quedan fuera de la Unión, se convertirían en terceros Estados (en el supuesto de ser reconocidos como tales $^{49}$ ) y deberían pedir el ingreso, caso de querer formar parte de la Unión Europea $^{50}$. Que lo lograran o no dependería del complicado proceso de adhesión regulado en los Tratados y que exige, en todo caso, la unanimidad de los Estados miembros. Estas advertencias han sido formuladas para rechazar las tesis de quienes sostenían — contra toda lógica jurídica — que un Estado surgido de la frag-

49 La Unión Europea y los Estados miembros nunca podrían reconocer a un Estado surgido de un proceso secesionista respecto a uno de ellos (salvo que este eventualmente lo hubiera consentido). Un proceso de esa naturaleza constituye por definición un atentado al principio de integridad territorial (consagrado en el artículo 4. 2 TUE), que vincula a la Unión y a sus miembros, impidiéndoles reconocer al pretendido nuevo Estado.

50 Esto fue señalado por primera vez con absoluta claridad por el Presidente de la Comisión, Romano Prodi, en febrero de 2004, ante el Parlamento Europeo: «cuando una parte del territorio de un Estado miembro deja de formar parte de ese Estado, por ejemplo porque se convierte en un Estado independiente, los tratados dejarán de aplicarse a este Estado. En otras palabras, una nueva región independiente, por el hecho de su independencia, se convertirá en un tercer Estado en relación con la Unión y, desde el día de su independencia, los Tratados ya no serán de aplicación en su territorio». Añadiendo que el nuevo Estado podría presentar la solicitud de ingreso en la Unión, lo que sólo lograría «si es aceptado por el Consejo por unanimidad». 
mentación de otro podía continuar en el seno de la Unión. Desde esta perspectiva, el recordatorio de lo obvio, esto es, de que abandonar el Estado (Reino Unido, España o el que sea) implica dejar de pertenecer a la Unión Europea, ha tenido efectos positivos. Pero, a pesar de ello, la posición oficial de la Comisión Europea da a entender que, desde una perspectiva estrictamente jurídica, la fragmentación de un Estado miembro es posible. Es decir, la Comisión sostiene que esa eventual fragmentación de un Estado miembro no sería contraria al Derecho Comunitario Europeo.

Desde esta óptica, la Unión Europea ha sostenido —y continúa haciéndoloque los conflictos secesionistas son asuntos internos de los Estados miembros que ellos mismos deben resolver y que, como tales, no afectan a sus relaciones con la Unión. En consecuencia, la Comisión Europea - y el resto de instituciones europeas- se limitan a permanecer como espectadoras de unos procesos en los que no se consideran legitimados para intervenir. Esta peligrosa y sorprendente postura se fundamenta en el supuesto silencio que el Derecho comunitario guarda sobre la cuestión y en una determinada interpretación del artículo 4. 2 del TUE.

La retirada de un Estado miembro - como hemos visto en el epígrafe anterior- tiene una cobertura jurídica expresa en los Tratados. Sin embargo, el caso de la secesión de una parte de un Estado no tiene cobertura jurídica alguna. No está contemplado por los Tratados. Algunos deducen de esa omisión, esto es, de la ausencia de una prohibición expresa, que está permitido. Es decir, que la secesión del territorio de un Estado no es contraria al Derecho comunitario europeo y que, por tanto, si un Estado miembro consiente su fragmentación, y con ello la reducción del territorio de la Unión, no está violando el Derecho Europeo. Frente a esta tesis, considero que una interpretación sistemática y teleológica de los Tratados conduce a entender lo contrario. Si los Tratados no prohíben los procesos separatistas es porque no se considera necesario hacerlo expresamente en la medida en que dicha prohibición se deduce de los valores, principios y fines de la Unión (arts. 23 y 4 TUE). Estos se sintetizan en la voluntad de alcanzar «una unión cada vez más estrecha entre los pueblos de Europa». Es evidente que el fortalecimiento de la Unión es absolutamente incompatible con la fragmentación de los Estados miembros. El único precedente que se puede invocar en sentido contrario no es tal. Me refiero a la independencia de Argelia respecto a Francia - ya vista en el epígrafe anterior-y ello porque se trata de un territorio que está en otro continente geográfico.

\section{El principio de cooperación leal (art. 4.3 TUE)}

Al ingresar en la Unión Europea en virtud del correspondiente Tratado de Adhesión, los Estados asumen el «acervo comunitario», e incorporan así a su derecho interno el derecho comunitario europeo en su totalidad. Los Estados se comprometen a respetar el cumplimiento de ese derecho en la totalidad de su 
territorio y en relación a toda su población ${ }^{51}$. El territorio de un Estado no es algo irrelevante para la Unión Europea. Antes al contrario, es el ámbito de aplicación espacial de su Derecho y de realización de sus políticas.

Si el Reino Unido o España —o cualquier otro Estado miembro- consiente la reducción de su territorio está afectando de forma negativa y grave a la Unión al fragmentar el espacio europeo: el mercado interior y el espacio de libertad y justicia. La secesión constituye una ruptura unilateral de la unidad de mercado y de la unión monetaria, implica la suspensión de la eficacia de los derechos y obligaciones derivados del acervo jurídico de la Unión y podría determinar también la retirada de la ciudadanía europea a los nacionales que viven en el territorio independizado. Por ello, desde un punto de vista jurídico, todo proceso secesionista (y a estos efectos tanto da que sea unilateral como pactado) implica la violación - manifiesta y grave- del artículo 4, apartado tercero, del TUE, auténtico pilar de la Unión Europea como Comunidad de Derecho:

«Conforme al principio de cooperación leal, la Unión y los Estados miembros se respetarán y asistirán mutuamente en el cumplimiento de las misiones derivadas de los Tratados.

Los Estados miembros adoptarán todas las medidas generales o particulares apropiadas para asegurar el cumplimiento de las obligaciones derivadas de los Tratados o resultantes de los actos de las instituciones de la Unión.

Los Estados miembros ayudarán a la Unión en el cumplimiento de su misión y se abstendrán de toda medida que pueda poner en peligro la consecución de los objetivos de la Unión.»

En su dimensión negativa, el principio de cooperación/lealtad se traduce en la prohibición del ejercicio abusivo de las competencias estatales, en la obligación de no ir contra los actos propios, y en la interdicción de suspender la reciprocidad de las obligaciones derivadas del derecho europeo. En su faceta positiva, el principio supone el compromiso de facilitarse cooperación mutua y de mantener relaciones institucionales fluidas y cordiales ${ }^{52}$.

Aplicando este principio, la competencia de los Estados miembros sobre su propio territorio reviste otro significado. Esa competencia no puede ser ejercida de forma abusiva. Y a la luz de esa lealtad federal, resulta abusivo aquel ejercicio que causa un perjuicio real y grave a la propia Unión. Es un ejercicio abusivo y prohibido en tanto que todos los Estados miembros están obligados a abstenerse «de toda medida que pueda poner en peligro la consecución de los objetivos de la Unión». La secesión es, sin duda, una medida de ese tipo.

51 Por todos, Alonso García, R.: Sistema jurídico de la Unión Europea, 4. ${ }^{a}$ edición, Civitas, Cizur Menor, 2014, pp. 275 y ss.

52 Blanquet, M.: L'article 5 du Traité CEE: resserche sur les obligations de fidelité des Etats membres de la Comunauté. LGDJ, Paris, 1994. 
La jurisprudencia constante y reiterada del Tribunal de Justicia de la Unión Europea sobre la primacía del derecho europeo sobre el derecho nacional debería disipar cualquier duda posible sobre esta cuestión. Desde el asunto Flaminio Costa (1964), el Tribunal afirmó que los Tratados prevalecen sobre cualquier norma de derecho interno incluso de rango constitucional. Un Estado no puede ampararse en su Constitución nacional para llevar a cabo un incumplimiento del derecho comunitario. Tampoco en una supuesta estructura constitucional que diera cobertura a la secesión (como se ha argumentado en el Reino Unido) ${ }^{53}$. Si pudiera hacerlo, el derecho comunitario no podría ser concebido como un auténtico ordenamiento jurídico, o dicho con mayor rotundidad no sería derecho. Por la misma razón, nadie discute que el principio de primacía opera también frente a cualesquiera reformas constitucionales que pueda emprender un Estado. Con independencia del contenido y efectos de estas reformas nunca podrían ser alegadas para incumplir una obligación derivada del Derecho Comunitario.

En este contexto, la fragmentación de un Estado puede ser considerada como el resultado de una reforma constitucional (para quienes conciben esta como una operación materialmente ilimitada) o como una destrucción constitucional (para los que defendemos que la reforma tiene unos límites materiales que no puede sobrepasar, y la unidad de la comunidad política es uno de ellos), pero al margen de ello, lo cierto es que para lo que nunca puede servir — desde el punto de vista del derecho europeo- es para dejar sin efecto el cumplimiento de las obligaciones derivadas de dicho ordenamiento. Entender lo contrario supone admitir que cualquier Estado miembro utilizando el expediente de una reforma/destrucción de su Texto Constitucional podría romper el mercado único y el espacio europeo de libertad y justicia, consintiendo la secesión de parte de su territorio nacional. Sólo desde un formalismo extremo podría replicarse que no hay incumplimiento alguno puesto que en el resto del territorio, el Estado miembro sigue cumpliendo sus obligaciones. Ello supone olvidar que desde la perspectiva de los fines atribuidos a la Unión en el artículo 3, el mantenimiento de su unidad es ya una obligación de todo Estado miembro.

Por todo lo anterior, es posible defender que una interpretación conjunta de los artículos 3 y 4 del TUE permite deducir de ellos la obligación de todo Estado miembro de mantenerse unido y de adoptar todas las medidas necesarias para evitar su fragmentación (y la del ámbito de aplicación espacial del derecho europeo).

53 «Al Derecho nacido del Tratado — afirma el Tribunal de Justicia de la Unión- surgido de una fuente autónoma, por su propia naturaleza no se le puede oponer ninguna norma del Derecho nacional, sin perder su carácter comunitario y sin que se cuestione el fundamento jurídico de la Comunidad misma»; de ahí que «la alegación de los derechos fundamentales, tal y como están formulados por la Constitución de un Estado miembro, o de los principios de una estructura constitucional nacional no pueden afectar a la validez de un acto de la Comunidad o a su efecto en el territorio de dicho Estado». Asunto Internationale Handelsgsellschaft (1970) 
Desde esta óptica, la fragmentación territorial —al margen de las previsiones establecidas en los Tratados-implica un atentado contra el principio de lealtad federal reconocido en el artículo 4. 3 TUE. Si un Estado miembro pactase la secesión de una parte de su territorio, estaría violando el artículo 4. 3 TUE según el cual los Estados «se abstendrán de toda medida que pueda poner en peligro la consecución de los objetivos de la Unión». Difícilmente puede cohonestarse con la lealtad federal europea la cancelación unilateral de la eficacia de las relaciones jurídicas de los Tratados y el derecho derivado en una parte de los Estados miembros. «En este sentido — escribe De Miguel — van contra este principio de lealtad federal tanto las autoridades regionales que llevan a cabo una declaración unilateral de independencia, como los Estados miembros que permiten que una parte de su territorio alcance la secesión de acuerdo a sus normas constitucionales internas sin tener en cuenta las normas e intereses de la UE» ${ }^{54}$.

Frente a ello no cabe oponer - como suele hacerse con frecuencia- el apartado anterior de la disposición citada, esto es el artículo 4. 2 del TUE: «La Unión respetará la igualdad de los Estados miembros ante los Tratados, así como su identidad nacional, inherente a las estructuras fundamentales políticas y constitucionales de éstos, también en lo referente a la autonomía local y regional. Respetará las funciones esenciales del Estado, especialmente las que tienen por objeto garantizar su integridad territorial, mantener el orden público y salvaguardar la seguridad nacional. En particular, la seguridad nacional seguirá siendo responsabilidad exclusiva de cada Estado miembro».

\section{El principio del respeto a la identidad constitucional de los Estados miembros (art. 4. 2 TUE)}

En virtud de este principio, la Unión no puede interferir en decisiones políticas fundamentales de los Estados miembros como las relativas a la forma de la jefatura del Estado, la forma de gobierno, o la articulación territorial del Estado. El respeto a la identidad nacional/constitucional supone que un Estado miembro puede organizarse territorialmente conforme a un sistema de centralización del poder político, o bien, adoptar una estructura federal. De ahí la referencia expresa a la autonomía regional y local. Según la interpretación mayoritaria, de este principio se deriva también el derecho de retirada recogido en el artículo 50 del Tratado.

Ahora bien, de este precepto no puede deducirse el derecho de los Estados a modificar unilateralmente su territorio, permitiendo, por ejemplo, la secesión de una parte del mismo. Esta interpretación no puede ser aceptada. Una cosa es que los Estados miembros puedan abandonar la Unión — de conformidad con el artí-

54 De Miguel, J.: La cuestión de la secesión..., ob. cit., p. 243. 
culo 50 TUE-, y otra muy distinta que, sin hacerlo, esto es, permaneciendo en ella, puedan modificar — unilateralmente- su territorio y fragmentar así el mercado interior y el espacio de libertad y justicia. El razonamiento jurídico en virtud del cual quien puede lo más (abandonar la Unión) puede lo menos (reducir su territorio y excluir sólo a una parte del mismo del ámbito de la Unión, tal y como pretendía hacer el Reino Unido) no es aquí aplicable. La razón es fácilmente comprensible. Si un Estado miembro abandona la Unión, queda —en principio- desvinculado del Derecho Europeo, y no cabe hablar de incumplimiento. Pero mientras un Estado permanezca dentro de la Unión está obligado a cumplir sus normas (art. 3 y 4.3 TUE), y entre ellas se encuentra la de garantizar su unidad territorial (y la del ámbito de aplicación espacial del derecho europeo). Los Estados tienen el deber de mantener íntegro su ámbito territorial con el fin de que el acervo comunitario se aplique sin reservas sobre el mismo. La secesión supone la quiebra de esa obligación porque, aunque se hiciera a través de un procedimiento constitucional interno previsto para el caso, supondría la suspensión del derecho de la Unión en una parte del ámbito espacial donde se aplica.

Por otro lado, de la misma forma que el derecho de retirada de la Unión no puede ejercerse unilateralmente, una eventual secesión pactada en el seno de un Estado miembro también habría de ser pactada con la propia Unión.

Como ha advertido De Miguel, «el respeto por la autonomía institucional nacional (art. 4.2 TUE) no puede justificar la ruptura unilateral de la unidad del mercado y del euro, la suspensión de la eficacia de los derechos y obligaciones derivados del acervo jurídico de la Unión y la retirada de la ciudadanía europea a los nacionales que viven en el territorio independizado» ${ }^{55}$.

El principio del respeto a la identidad constitucional no es ni absoluto ni ilimitado. En este sentido, algunos autores interpretan el artículo 6 TUE como una cláusula de homogeneidad federal (respeto al principio democrático y a los derechos fundamentales) ${ }^{56}$. Es lógico que sea así. El principio en cuestión no permite, por tanto, que un Estado miembro deje de ser un Estado constitucional. Si lo hiciera, se activarían los procedimientos de coerción federal previstos en el artículo 7 TUE. Por razones similares, del principio de identidad constitucional tampoco se puede derivar — tal y como hacen algunos - la facultad de los Estados miembros de disponer sobre su propio territorio y en definitiva sobre su continuidad como Estados no fragmentados. Una reforma de su ordenamiento interno llevada a cabo por un Estado miembro contraria a los derechos fundamentales vulneraría el artículo 6 TUE. Una eventual reforma constitucional que diera cabida a la secesión de una parte del territorio atentaría contra el artículo 4.3 TUE antes examinado. En ninguno de los dos casos cabría apelar al artículo 4. 2.

55 De Miguel, J.: La cuestión de la secesión..., ob. cit., p. 243.

56 Atripaldi, V., y Miccu, R. (eds.): L'omogeneità costituzionale nell'Unione Europea, CEDAD, Milán, 2003. 
El artículo 4. 2 ni fue concebido ni puede ser interpretado como una vía para dejar sin efecto las obligaciones «constitucionales» de los Estados miembros incluidas en los arts. 4.3 y 6 TUE. El respeto a la identidad constitucional de los Estados miembros no implica, por tanto, que la Unión y los Estados deban considerarse ajenos - $\mathrm{y}$ limitarse por ello al papel de pasivos espectadores - al proceso de destrucción de uno de ellos por muy "pactado» que, desde el punto de vista del derecho interno, se presente (caso de Escocia). Y mucho menos, claro está, si el fenómeno secesionista se plantea de forma unilateral en flagrante violación del Derecho interno (caso de Cataluña).

La interpretación que del artículo 4. 2 del TUE hacen algunos en el sentido de ver en él la base jurídica que el Derecho europeo ofrece para que un Estado miembro se fragmente (si tal es su voluntad política) debe ser rechazada. Se trata de una interpretación que atribuye a la disposición que nos ocupa una finalidad absolutamente contraria a la que le otorgaron sus autores ${ }^{57}$. Desde esta óptica, el hecho de que el principio de la «identidad nacional» o «constitucional» esté concebido como una garantía de la existencia misma del Estado miembro, - $-\mathrm{y}$ que, por tanto, la Unión debe respetar-, impide cualquier interpretación del artículo 4.2 en el sentido, de que la existencia misma (su conservación como una unidad de acción y decisión política) de un Estado miembro sea algo ajeno a la Unión Europea. Esto supone transformar radical —e ilegítimamente- el significado y alcance del principio. Un principio configurado para garantizar la existencia y conservación de los Estados miembros (frente a la Unión) se ha utilizado - y continúa utilizándose por parte de algunos- para justificar la inacción y la pasividad de la Unión frente a los intentos de destrucción de un Estado miembro por fuerzas secesionistas o movimientos separatistas de diversa índole. Nadie pudo nunca prever que el respeto del principio de identidad nacional y constitucional para lo que iba servir era para dar cobertura jurídica a la posible fragmentación de un Estado desde la perspectiva del derecho europeo.

En definitiva, la interpretación del artículo 4 del TUE vigente en algunos discursos y en cierta praxis de las instituciones europeas es contraria a todos los cánones de interpretación admisibles en Derecho:

a) De una interpretación teleológica del principio de identidad nacional no se puede deducir que la conservación o fragmentación de un Estado miembro sea un asunto interno de éste, y como tal ajeno a la Unión Europea. Al contrario, su recepción en los Tratados implica un compromiso activo por parte de la Unión y de sus instituciones en defensa de esa «identidad» en aquellos casos en que se ve existencialmente amenazada por fuerzas o procesos secesionistas.

57 El precepto que comentamos fue introducido a iniciativa de España con la intención de reforzar el principio de integridad territorial de los Estados miembros.

UNED. Teoría y Realidad Constitucional, núm. 37, 2016, pp. 347-379 
b) De una interpretación teleológica del principio de cooperación leal y del cumplimiento de las obligaciones derivadas del derecho europeo no se puede concluir que la fragmentación de un Estado, — por la secesión de una parte de su territorio- sea una opción que este pueda contemplar, sin más consecuencias que la salida de ese territorio «independizado» de la Unión.

Una interpretación sistemática del artículo 4 en su conjunto, y en el contexto del Título I del Tratado, singularmente, los fines atribuidos a la Unión en el artículo 3, conduce, inexorablemente, a una conclusión muy diferente a la mantenida por el discurso europeo oficial. Y esa conclusión es que los fenómenos secesionistas son problemas que afectan directamente a la Unión Europea. No son meros asuntos internos de los Estados miembros. Resulta completamente absurdo seguir considerando el separatismo un problema interno, cuando es evidente que la secesión reduciendo el territorio de la Unión, repercute sobre el ámbito de aplicación del Derecho comunitario, fragmenta el mercado único y el espacio de seguridad y justicia común, y contradice los valores fundacionales del proyecto europeo. Por ello mismo, carece igualmente de fundamento seguir afirmando que el Tratado guarda silencio sobre la posibilidad (jurídica) de que un Estado miembro se desintegre. En relación con ello, de los artículos 3 y 4 . 3 del TUE se puede deducir con meridiana claridad la existencia de una obligación jurídica por parte de todo Estado miembro de la Unión de mantenerse unido y evitar su fragmentación. Y ello porque el mantenimiento de esa unidad resulta imprescindible para garantizar el cumplimiento del derecho comunitario en su territorio. Al mismo tiempo, del artículo citado cabe deducir igualmente la obligación de la Unión — derivada de los principios de cooperación leal y de respeto a la identidad constitucional de los Estados- de no permanecer pasiva ante un proceso secesionista. Obligación que resulta incompatible con el discurso actual de seguir considerando esos procesos como asuntos internos.

La Comisión Europea - como guardiana de los Tratados - no ha estado a la altura de las circunstancias. Políticamente ha transmitido la imagen de una institución más preocupada porque un Estado se exceda en algunas décimas en su déficit público anual que por su posible fragmentación. Jurídicamente no ha velado por el cumplimiento de los Tratados al realizar una interpretación de los mismos incompatible — por las razones expuestas anteriormente- con el principio de primacía del derecho comunitario.

\section{Consecuencias jurídicas y políticas de la secesión}

De todo lo anterior se deduce que la secesión tanto unilateral como pactada es contraria al Derecho europeo. Una decisión nacional que implique la secesión de una región supondría un acto ilícito aunque no inválido, del derecho comunitario, en la medida en que no existe un poder de coerción de las instituciones 
europeas para castigar al Estado o territorio incumplidores. Desde el punto de vista del Derecho Constitucional interno, la secesión —al no estar permitida por la Constitución - se configura como un acto ilícito e inválido, por lo que puede y debe ser desconocido por los poderes centrales del Estado que están facultados para emplear todas las medidas necesarias para restablecer la legalidad ${ }^{58}$.

Ahora bien, que se trate de un acto ilegal no quiere decir que no tenga efectos. Los tendría, en el supuesto de que como situación fáctica lograra imponerse sobre el orden jurídico constituido. Por ello es preciso describir siquiera brevemente las consecuencias derivadas de una secesión para el Estado matriz y para el nuevo Estado.

a) En relación con el estado matriz se plantea la cuestión de si podrá seguir formando parte de la Unión o no. La sucesión en la calidad de miembro de una organización internacional debe analizarse desde la perspectiva de las normas y la práctica de la organización internacional de que se trate. En el caso de la Unión Europea (y lo mismo cabe decir respecto a otras como la ONU o la Alianza Atlántica), la pérdida de la condición de miembro sólo se produciría si se extinguiera la personalidad jurídica internacional. Es decir, salvo que el Estado matriz en cuestión (Reino Unido, España, u otro) desapareciera como sujeto de derecho internacional, conservaría su condición de miembro de la Unión Europea ${ }^{59}$. La extinción de la personalidad jurídica solo se produciría en el caso de disolución pactada del Estado (como ocurrió en Checoslovaquia en $1990^{60}$ ) o cuando la fragmentación del estado matriz hiciese irreconocible la estructura estatal previa (Yugoeslavia).

En este contexto, si un Estado miembro de la UE (Reino Unido, España u otro) pierde una parte de su territorio y población como consecuencia de un proceso de secesión, mantendría su condición de Estado miembro ${ }^{61}$. Ahora bien, en el plano institucional se producirían importantes modificaciones. Dado que la población del Estado es un elemento fundamental para determinar la atribución de votos en el Consejo de la UE, la reducción del número de habitantes supondrá una pérdida de votos. El número de miembros en el Parlamento Europeo se verá reducido por la misma razón. Sin embargo,

58 DíEz-PicAzo, L.M.: «La naturaleza de la Unión Europea» en InDret, n. ${ }^{\circ}$ 4, 2008, p. 23.

59 El Informe del Gobierno británico — elaborado sobre la base de los dictámenes de numerosos internacionalistas consultados - sostiene que - tras una eventual independencia de Escocia - el Reino Unido conservaría su condición de miembro de la UE y que no la eventual pérdida de población y territorio no alteraría sus derechos y obligaciones. CRAWFORD, J. y BOYLE, A.: Opinion: Referendum on the Independence of Scotland. International Law Aspects. February, 2013.

60 Young, R.: «The Breakup of Czechoslovakia», Institute of Intergovernmental Relations, Research Paper n. ${ }^{\circ} 32,1994$

61 Andrés Sáenz de SAntamaría, M. P. «Problemas actuales de la sucesión de Estados», en VV.AA.: Curso de Derecho Internacional de Vitoria-Gasteiz, 1993, Universidad del País Vasco, Bilbao, 1995, p. 212. 
como advierte De Miguel, esta cifra siempre será relativa, pues al existir una cifra tope de europarlamentarios, a partir de 2014, cada vez que haya una nueva ampliación los Estados miembros verán reducido el número de parlamentarios que tienen atribuidos para todos y en años sucesivos. Lo mismo ocurrirá con respecto al Consejo Económico y Social o el Comité de las Regiones. Por lo demás, como ha recordado Mangas, el Estado miembro que permanezca en la UE no verá afectada su presencia en el Consejo Europeo, la Comisión, el Tribunal de Cuentas o el Banco Central Europeo ${ }^{62}$.

Estos ajustes requerirían reformas del derecho europeo. Como la requiere la adhesión de cualquier Estado. Esta reforma vendría a convalidar la secesión como situación de hecho. Reconocería la perdida de población y territorio del Estado miembro y adaptaría el Derecho Europeo a la nueva situación. En todo caso, esta adaptación en modo alguno implicaría el reconocimiento jurídico del nuevo Estado.

b) El nuevo Estado — surgido de la separación del Estado matriz — tendría que lograr el reconocimiento de los demás para convertirse en un nuevo sujeto de Derecho Internacional. En el supuesto de que lo consiguiera ninguna duda cabe que los Tratados no prevén ningún tipo de posible reingreso automático en la Unión Europea. El nuevo Estado es un tercer Estado para la UE y en el supuesto de que desee adherirse a ella deberá solicitarlo formalmente. Su integración dependerá del cumplimiento de los criterios generales de Copenhague, de los que le fije el Consejo Europeo, y de la superación de los trámites procedimentales previstos en el artículo 49 TUE. Las decisiones relativas al ingreso de nuevos socios exigen la unanimidad de los miembros.

Conviene recordar, en este sentido, que el artículo 50. 5 TUE exige que el Estado que se haya retirado de la Unión en ejercicio del derecho previsto en el mismo precepto, se someta al procedimiento formal de adhesión, si solicitare nuevamente su ingreso en la UE.

El eventual ingreso del nuevo Estado requeriría modificar los Tratados: para incluir su nombre en el artículo 52 (relación de Estados miembros); su lengua oficial en el artículo 55; y sobre todo, regular su participación en las instituciones.

\section{CONCLUSIONES}

La principal conclusión que cabe extraer de este trabajo es que la secesión es un fenómeno que provoca inestabilidad e incertidumbre, tanto en el ámbito de

62 Mangas Martín, A.: «La secesión de territorios en un Estado miembro: efectos en el derecho de la Unión Europea», op. cit., p. 60. 
los Estados como en el de la Unión Europea. Los intentos de limitar sus potenciales efectos destructivos y disgregadores a través del Derecho no pueden hacernos olvidar que existe una incompatibilidad radical entre la secesión como categoría y el Estado de Derecho como paradigma (o Comunidad de Derecho en el caso de la Unión Europea). El Presidente norteamericano A. Lincoln era plenamente consciente de esta incompatibilidad cuando al asumir la presidencia de los EE. UU. recordó que «la secesión es la esencia misma de la anarquía, porque, si un Estado se separa, también puede separarse cualquier otro, hasta que no quede nada del Gobierno ni de la nación ${ }^{63}{ }$.

De Miguel, que se ha ocupado con rigor y detalle de esta problemática, advierte como «la inestabilidad institucional que introduce la incorporación de la cláusula de secesión a cualquier sistema político, es plenamente aplicable tanto a la UE como a un Estado constitucional, pues introduce elementos de incertidumbre en todos los planos del proceso político» ${ }^{64}$.

En el ámbito de la Unión Europea, el artículo 50 TUE que regula la secesión de un Estado (derecho de retirada) respecto a la UE es problemático. Por otro lado, la lectura que algunos hacen del Tratado según la cual, los procesos de secesión en el seno de los Estados miembros son asuntos internos de estos sobre los que ni las instituciones ni el derecho de la Unión tienen nada que decir, resultan tan sorprendentes como peligrosas.

En el confuso y peligroso contexto descrito en este trabajo, urge dar una respuesta política y jurídica al problema de la secesión: ¿Qué puede hacer la Unión Europea para que no vuelva a repetirse un experimento con un potencial desestabilizador tan formidable como el sufrido en Escocia? En España, Bélgica, Italia, Chipre, Rumanía o Eslovaquia, por citar sólo algunos casos muy claros, fuerzas políticas independentistas apelan al precedente escocés como modelo. A partir de ahora, debería quedar muy claro que no es un modelo válido para la Unión Europea.

La Unión Europea debe recordar, ante todo y sobre todo, que los procesos secesionistas son contrarios a los valores y principios fundacionales del proyecto europeo. Y que esa incompatibilidad no sólo es política, sino que también lo es desde un punto de vista jurídico. Como he expuesto en las páginas precedentes la fragmentación de un Estado miembro por secesión de una parte de su territorio resulta incompatible con los artículos 3 y 4 del TUE. A la vista de la confusión existente y ante la gravedad de las amenazas que se ciernen en el futuro sobre el proyecto de integración europea sería conveniente que las instituciones europeas entraran al fondo del problema.

Lo deseable — una vez más_ sería emprender una reforma de los Tratados que cerrarse la vía — de forma clara y definitiva — a cualquier aventura o experi-

63 Muchnick, M.: «Lo que de verdad le importaba a Lincoln» en EL PAIS, 8 de noviembre de 2014.

64 De Miguel, J.: La cuestión de la secesión..., ob. cit., p. 224. 
mento secesionista. Se trataría de introducir en el Tratado una regulación expresa que no sólo prohibiera todo proceso de secesión en un Estado miembro, sino que garantizara también que, en el supuesto de que dicha prohibición no fuera respetada, el pretendido nuevo Estado nunca podría ser admitido en la Unión. En todo caso, y mientras no se plantee un proceso de reforma de los Tratados (que por otro lado la crisis de la eurozona hace de él un objetivo ineludible) las instituciones — cada una en el ámbito de sus competencias- deberían contribuir a clarificar la situación y a conjurar las amenazas secesionistas.

El Consejo Europeo - por unanimidad - y el Parlamento Europeo - por una mayoría muy cualificada de representantes de los partidos europeístas-, deberían aprobar sendas declaraciones políticas recordando, por una parte, que el Derecho Comunitario implica la prohibición por parte de los Estados miembros de consentir cualquier secesión dentro de un Estado miembro; y formulando también, como advertencia general, la prohibición de ingreso de cualquier Estado surgido de la fragmentación de otro. Para ello habría que incluir esta advertencia en los denominados criterios de Copenhague. Al fin y al cabo resulta absolutamente incomprensible que, quien aspira a una soberanía propia e ilimitada, y para ello quiere independizarse de un Estado, sea admitido en una organización cuya razón de ser y finalidad es precisamente compartir la soberanía.

En la Europa del siglo Xxi, la ruptura de una comunidad política y la fragmentación de una sociedad no pueden presentarse nunca como un objetivo democrático legítimo. El derecho de secesión sólo puede justificarse — desde un punto de vista ético y jurídico - en el caso de comunidades cuyos miembros no vean respetados sus derechos fundamentales. Y es evidente que no es el caso del Reino Unido ni de España ni de Bélgica, ni de Italia... Y en el supuesto de que un Estado miembro de la Unión Europea sufriera una involución democrática — como podría ser el caso de Hungría - la respuesta jurídica y política a ese problema nunca sería la fragmentación del Estado.

Por otro lado, y por lo que se refiere a la propia UE, el potencial efecto desestabilizador del artículo 50 sólo desaparecerá cuando la Unión se convierta en una auténtica Unión Política, es decir, en una comunidad política federal dotada de una auténtica Constitución: «Una unión indestructible de Estados indestructibles», recordando las palabras del Tribunal Supremo de los EE. UU ${ }^{65}$.

$$
* * *
$$

TITLE: Secession and European Law

ABSTRACT: This article analyzes the meaning of secession in international and constitutional law. It also examines the phenomenon of secession in European law. This requires studying two types of problems: the

65 Reed Amar, A.: «Of Sovereignty and Federalism», The Yale Law Journal, Vol. 96, n. ${ }^{\circ}$ 7, 1987, pp. $1425-1520$

UNED. Teoría y Realidad Constitucional, núm. 37, 2016, pp. $347-379$ 
secession of a member state of the European Union and the fragmentation of a Member State for the secession of part of its territory. The conclusion is that conservation or fragmentation of a Member State of the European Union is not an internal matter. In our opinion, the political and legal system of the Union can be characterized also federally, which prevents the national and regional authorities to carry out unilateral acts that go against the principle of Community federal loyalty and European citizenship.

RESUMEN: Este artículo analiza en primer lugar el significado de la secesión en el Derecho Internacional y en el Derecho Constitucional. Asimismo, examina cómo se aborda el fenómeno de la secesión en el Derecho comunitario europeo. Esto obliga a estudiar dos tipos de problemas: por un lado, el de la secesión de un Estado miembro respecto de la propia Unión; por otro, el de la fragmentación de un Estado miembro por la secesión de una parte de su territorio. La conclusión es que la conservación o fragmentación de un Estado miembro de la Unión Europea no es un asunto interno: la secesión de partes de un territorio afecta al sistema político europeo en su conjunto, en la medida en que es una forma de integración federal donde no caben actos unilaterales que quebranten el principio de lealtad federal de la Unión y la ciudadania europea que ba ido conformándose en las últimas décadas.

KEY WORDS: European Union; member state; secession; federal loyalty; constitutional amendment.

PALABRAS Clave: Unión Europea; Estados miembros; secesión; lealtad federal; reforma constitucional.

FECHA DE RECEPCIÓN: 30.10 .2015

FECHA DE ACEPTACIÓN: 15.01.2016 